\title{
Mitochondrial DNA in pediatric leukemia patients
}

\author{
Agata Kodroń1凶, Magda Ghanim', Katarzyna K. Krawczyk1, \\ Anna Stelmaszczyk-Emmel2 ${ }^{2}$ Katarzyna Tońska ${ }^{1}$, Urszula Demkow² and Ewa Bartnik1,3凶
}

IInstitute of Genetics and Biotechnology, Faculty of Biology, University of Warsaw, Warsaw, Poland; 2Department of Laboratory Diagnostics and Clinical Immunology of Developmental Age, Medical University of Warsaw, Warsaw, Poland; ${ }^{3}$ nnstitute of Biochemistry and Biophysics, Polish Academy of Sciences, Warsaw, Poland

\begin{abstract}
Numerous studies of mitochondrial DNA (mtDNA) in cancer have shown differences between mtDNA sequences in tumor and normal tissue and at various stages of cancer treatment in the same patient. However, there is little data on acute lymphoblastic leukemia (ALL), the most common type of leukemia in children. In this study we compared mitochondrial sequence variation in the $D$ loop region and in 5 genes of mtDNA in bone marrow samples of 6 pediatric patients with ALL at various stages of therapy. We found several common polymorphisms and one variant at position 3688 whose level varied during leukemia treatment. Our results suggest that mitochondrial DNA mutations, whose levels change during patient treatment, could be potential biomarkers for monitoring treatment efficacy and disease progression.
\end{abstract}

Key words: pediatric ALL, mtDNA, chemotherapy

Received: 20 October, 2016; revised: 11 November, 2016; accepted: 06 December, 2016; available on-line: 09 March, 2017

\e-mail: ebartnik@igib.uw.edu.pl (EB), agatakodron@wp.pl (AK) Abbreviations: mtDNA, mitochondrial DNA; ALL, acute lymphoblastic leukemia; D-loop, displacement loop

\section{INTRODUCTION}

Mitochondria are responsible for energy production during cellular respiration. They contain their own circular DNA of about $16.5 \mathrm{~kb}$. The mitochondrial DNA (mtDNA) consists of the coding region and the so-called displacement loop (D-loop) of 1124 bp, which contains transcription and replication initiation sites. mtDNA is more susceptible to damage than nuclear DNA mainly due to less efficient DNA repair systems, the lack of protection of genetic material by histone proteins and mutagenic effects of free radicals generated in the process of oxidative phosphorylation (OXPHOS) in mitochondria. So far, over $100 \mathrm{mtDNA}$ point mutations causing human disease have been detected, and more mutations are discovered every year (Kim et al., 2008).

Hematological malignancies represent $44.9 \%$ of all neoplasms in patients under 18 years of age. The term leukemia refers to a family of malignant neoplasms of the bone marrow characterized by uncontrolled proliferation of hematopoietic stem cells which do not differentiate into normally functioning blood cells and interfere with the production of other types of healthy cells in the bone marrow (Nordlund, 2007). In general leukemia can be divided into two types based on which white blood cells are affected: lymphoblastic leukemia affects cells of the lymphoid line and myeloblastic leu- kemia affects cells of the myeloid line. Lymphoid neoplasms are assigned to two main categories: derived from $\mathrm{B}$ or $\mathrm{T}$ lineage lymphoid precursors. The most common in children is acute lymphoblastic leukemia (ALL) (de Rooij et al., 2015). Approximately 80-85\% childhood ALL are of a precursor B phenotype. Immunophenotype analysis allows subclassification of B-lineage ALL into pro-B ALL, common ALL (cALL), preB ALL and mature B-cell ALL (Chiaretti et al., 2014). There are multiple genetic and environmental risk factors contributing to the development of this type of cancer. In some patients chromosomal alterations like translocations or hyperdiploidy as well as mutations or gene fusions (like $B C R / A B L$ or TEL/AML1) occur in lymphoid or myeloid progenitor cells, causing their dysfunction (Rubnitz \& Pui, 1997; Buffler et al., 2005). Although most studies focus on the analysis of nuclear DNA alterations, an increased interest in the potential influence of mutations and polymorphisms in the mitochondrial genome on leukemogenesis is observed. Somatic mtDNA mutations were detected in $40 \%$ of adult leukemia patients (He et al., 2003). Few studies on monitoring changes in mutation level at different cancer stages and at different levels of treatment have been conducted. In one study on adult ALL patients changes in mtDNA sequence in different leukemia stages and at different stages of the treatment were observed (He et al., 2003). In one patient the mtDNA mutation in bone marrow cells $(15296 \mathrm{~A}>\mathrm{G}$ in the cytochrome $b$ gene) was lost in hematological remission and reappeared when the patient relapsed and played the role of a clonal marker for the leukemia. These investigations have not been reproduced. It is also possible that chemotherapy could contribute to cancer relapse by damaging DNA and generating new mutations. However, little is known about mtDNA damage caused by anticancer agents. Many chemotherapeutic agents are mutagenic to nuclear DNA, but their influence on mtDNA has not been widely explored. Despite the abundance of data about alterations in mtDNA in many types of cancers, so far little is known about the changes in mtDNA mutation levels in people, especially in children, suffering from proliferative disorders of the bone marrow. The described data about mitochondrial DNA variation in different types of leukemia mainly come from analyses of adult patient tissues and do not necessarily reflect changes in the mtDNA that occur during the development of ALL in children. In this study we examined alterations of the D-loop region and in 5 genes of $\mathrm{mtDNA}$ in bone marrow cells from pediatric patients with ALL. 
Our aim was to investigate whether chemotherapy causes any changes in the mtDNA sequence. Another goal was to find polymorphisms or mutations with levels changing during chemotherapy, which could aid in monitoring treatment.

\section{MATERIALS AND METHODS}

Patients. Newly diagnosed ALL patients under 18 years of age were selected for the study in 2009 in the Department of Laboratory Diagnostics and Clinical Immunology of Developmental Age, Medical University of Warsaw. The material was 6 bone marrow samples (from 4 boys and 2 girls) remaining after routine biopsies taken at the time of diagnosis and at different times of treatment of the patients. The study was approved by the Independent Ethics Committee of the Medical University of Warsaw.

Diagnostic procedure and treatment. A diagnosis of leukemia was based on studies of bone marrow cells (BM), peripheral blood (PB) and cerebrospinal fluid (CSF). Obligatory diagnostics of ALL included: cytomorphological studies (smears stained by the May-GrünwaldGiemsa method in BM, PB and CSF), flow cytometry (immunophenotype, DNA index in BM/PB), cytogenetic analyses ( $\mathrm{G}$ binding patterns of high resolution chromosomes in $\mathrm{BM} / \mathrm{PB}$ ) and molecular studies (RT-PCR for selected genes: BCR/ABL, MLL/AF4, TEL/MLL1 in $\mathrm{BM} / \mathrm{PB})$. Four patients were treated according to ALL IC-BFM 2002 protocol (Stary et al., 2013), one according to ALL IC-BFM 2009 protocol (Campbell et al., 2009) and one according to INTERFANT 06 protocol (Pieters et al., 2006). Information about patients, the protocols which were used during treatment and the time when the second samples, collected during treatment, were received are shown in Table 1.

DNA isolation. The material was total DNA isolated from cryopreserved bone marrow cells. Isolation of DNA was performed by the phenol:chloroform method. Thawed cells were suspended in a lysis buffer comprising water, $10 \mathrm{mM}$ Tris- $\mathrm{HCl}(\mathrm{pH} 7.4), 10 \mathrm{mM} \mathrm{NaCl}$, $10 \mathrm{mM}$ EDTA, 5\% SDS and $20 \mathrm{mg} / \mathrm{ml}$ Proteinase $\mathrm{K}$ and placed at $37^{\circ} \mathrm{C}$ for 24 hours. After digestion, lysates were mixed with an equal volume of phenol (Sigma) and centrifuged at $12000 \mathrm{rpm}$ for $15 \mathrm{~min}$ at room temperature. The aqueous phase was transferred to new tubes and mixed with an equal volume of phenol:chloroform (1:1) and centrifuged again. The aqueous phase was collected and mixed with an equal volume of chloroform and centrifuged in the same conditions. After centrifugation the aqueous phase was collected and mixed with 0.1 volumes of $4 \mathrm{M} \mathrm{NaCl}$ and 2.5 volumes of ice-cold ethanol and placed at $-20^{\circ} \mathrm{C}$ overnight. DNA was precipitated by centrifugation at $13000 \mathrm{rpm}$ for $15 \mathrm{~min}$, the

Table 1. Clinical details of pediatric leukemia patients.

\begin{tabular}{|c|c|c|c|c|c|}
\hline Patient & Diagnosis & $\begin{array}{l}\text { Age } \\
\text { (years) }\end{array}$ & Gender & Protocol of treatment & $\begin{array}{l}\text { Second bone marrow } \\
\text { sample (day of treatment) }\end{array}$ \\
\hline P1 & pro-B ALL/CALL & 3 & Female & ALL IC-BFM 2002 & 48 \\
\hline P2 & pro-B ALL/CALL & 14 & Male & ALL IC-BFM 2002 & 41 \\
\hline P3 & cALL + coexpression of CD33 & 3 & Male & ALL IC-BFM 2002 & 96 \\
\hline P4 & cALL & 9 & Female & ALL IC-BFM 2002 & 25 \\
\hline P5 & CALL & 17 & Male & ALL IC-BFM 2009 & 80 \\
\hline P6 & pro-B ALL + coexpression of CD65, CD15, NG2 & 8 months & Male & INTERFANT 06 & 15 \\
\hline
\end{tabular}

pellet was washed once with $75 \%$ ethanol, dissolved in water and stored at $-20^{\circ} \mathrm{C}$.

PCR of the mtDNA and sequencing. The D-loop region and $5 \mathrm{mtDNA}$ genes (ATPase6, ATPase8, ND1, cytB, COXII) were amplified by PCR. PCR was done in a final volume of $50 \mu \mathrm{l}$ with M13-tagged primers to facilitate the direct sequencing of the PCR-amplified products (Table 2). PCR conditions for amplification were: initial denaturation at $94^{\circ} \mathrm{C}$ for 3 min; 35 cycles of denaturation at $94^{\circ} \mathrm{C}$ for $30 \mathrm{~s}$; annealing at $58^{\circ} \mathrm{C}$ for $30 \mathrm{~s}$; elongation at $72^{\circ} \mathrm{C}$ for $1 \mathrm{~min}$. The PCR reaction mixture contained 100 ng DNA template, $400 \mu \mathrm{M}$ dNTP (A\&A Biotechnology), $0.2 \mu \mathrm{M}$ of each primer, 1x buffer for Walk polymerase (A\&A Biotechnology) and 1.25 U Walk DNA polymerase (A\&A Biotechnology). Following PCR amplification, samples were purified to remove unincorporated primers and sequenced directly on the ABI3730xl DNA Analyzer (Applied Biosystems). The obtained sequences were compared directly to the revised Cambridge reference sequence (rCRS) using Sequencher 4.1.4 software. Description of the primers used in amplification of different regions of mtDNA are presented in Table 2.

Analysis of the $3688 \mathrm{G}>\mathrm{A}$ mutation. The heteroplasmy level of the $3688 \mathrm{G}>\mathrm{A}$ mutation was determined by last cycle hot PCR-RFLP. The region spanning this mutation was PCR amplified. PCR was performed in a final volume of $25 \mu \mathrm{l}$ using the following primers: forward, 3659-3687 (C/G mismatch at position 3687 introduces a restriction site for HaeIII endonuclease in the wild type sequence), reverse 3809-3790. PCR conditions for amplification were the same as previously described. The PCR product was radiolabeled with $\alpha$-32P-dATP in an additional PCR cycle. The $151 \mathrm{bp}$ product was cut with HaeIII restriction enzyme and separated on a $12 \%$ nondenaturing polyacrylamide gel. The wild type sequence is cut into two fragments of $121 \mathrm{bp}$ and $30 \mathrm{bp}$. The sequence containing the $3688 \mathrm{G}>\mathrm{A}$ transition was not cleaved. The radioactivity in each fragment was quantified using MultiGauge V3.0 software.

\section{RESULTS}

\section{Mitochondrial DNA sequence variation in bone marrow cells prior to chemotherapy treatment}

We compared sequences of the D-loop and 5 genes of the mitochondrial genome (ATPase6, ATPase8, ND1, cytB, COXII) from bone marrow cells collected at the time of diagnosis from 6 leukemic patients to the rCRS. This comparison revealed the presence of several changes. Almost all of found changes in the analyzed regions of the mtDNA were microsatellite variations, variants defining mitochondrial haplogroups and common population polymorphisms according to the Human Mitochon- 
Table 2. Primers for D-loop, ATPase 6, ATPase 8, ND1, cytB, COXII gene amplification and their nucleotide sequences.

Each starter has a M13 tagged tail. The sequence of the FM13 tail: 5'TAAAACGACGGCCAGT3' and of the RM13 tail: 5'CAGGAAACAGCTATGACC3'.

\begin{tabular}{|c|c|c|c|}
\hline primer name & primer sequence $\left(5^{\prime}-3^{\prime}\right)$ & nucleotide position $\left(5^{\prime}-3^{\prime}\right)$ & mtDNA region \\
\hline M13.D1F-M13.D3R & $\begin{array}{l}\text { D1F: AATGGGCCTGTCCTTGTAG } \\
\text { D3R: GGTGTGGCTAGGCTAAGC }\end{array}$ & $15879-803$ & D-loop \\
\hline $\begin{array}{l}\text { M13.5F-M13.5R } \\
\text { M13.6F-M13.6R } \\
\text { M13.7F-M13.7R }\end{array}$ & $\begin{array}{l}\text { 5F: GGATCAGGACATCCCGATG } \\
\text { 5R: AACGGCTAGGCTAGAGGTG } \\
\text { 6F: TAGCTCTCACCATCGCTC } \\
\text { 6R: GATTGTTAATGGGTATGGAGAC } \\
\text { 7F: TCCTACCACTCACCCTAGC } \\
\text { 7R: GTCATGTGAGAAGAAGCA }\end{array}$ & 2995-4869 & ND1 \\
\hline $\begin{array}{l}\text { M13.12F-M13.12R } \\
\text { M13.13F-M13.13R } \\
M 13.14 F-M 13.14 R\end{array}$ & $\begin{array}{l}\text { 12F: CCTAATTAGTAGAAGAACCCTC } \\
\text { 12R: CTCGATTGTCAACGTCAAGG } \\
\text { 13F: ATTATCCTAGAACCAGGCG } \\
\text { 13R: TGATGAGATATITGGAGGTGG } \\
\text { 14F: ACAATCCTAGGCCTACCCG } \\
\text { 14R: GATAGGCATGTGATTGGTGG }\end{array}$ & $7349-9231$ & COXII, ATPase8, ATPase6 \\
\hline $\begin{array}{l}\text { M13.23F-M13.23R } \\
\text { M13.24F-M13.24R } \\
\text { M13.25F-M13.25R }\end{array}$ & $\begin{array}{l}\text { 23F: CCCATAATCATACAAAGCCC } \\
\text { 23R: GTTGAGGCGTCTGGTGAG } \\
\text { 24F: ACTACAAGAACACCAATGACC } \\
\text { 24R:TGTAGTAAGGGTGGAAGGTG } \\
\text { 25F: TAGGAATCACCTCCCATTCC } \\
\text { 25R: GTCAATACTTGGTGGTACC }\end{array}$ & $14227-16067$ & cytB \\
\hline
\end{tabular}

drial Genome Database ( $\mathrm{mtDB}$, Department of Genetics and Pathology Uppsala University, Sweden, updated 1st of March 2007, www.mtdb.igp.uu.se) and according to MITOMAP database (www.mitomap.org). The highest level of polymorphisms were found in D-loop region and in the cytB gene. Only in patient 2 a change at position 3688 in ND1 gene was found. This change was not listed as a polymorphism in mtDNA databases. This transition results in substitution threonine for alanine (A128T) in a highly conserved residue of the protein (Fig. 1). All the detected changes were homoplasmic except the change at position 3688 which was found to be heteroplasmic. Mitochondrial DNA sequence variations in bone marrow cells in analyzed patients are shown in Table 3 in Appendix 1 (at www.actabp.pl).

\section{Search for disease and treatment markers in mtDNA sequence}

In order to explore the possibility that treatment can cause mtDNA mutations and to look for possible markers of the disease, the control region and 5 genes of mtDNA (ATPase6, ATPase8, ND1, cytB, COXII) were analyzed for 6 patients using DNA isolated from bone marrow collected at the time of ALL diagnosis and several days/months later when patients were undergoing chemotherapy. We did not find additional changes

Patient
Homo sapiens
Gorilla gorilla
Pan paniscus
Pongo pygmaeus
Danio rerio
Drosophila melanogaster
Canis lupus familiaris

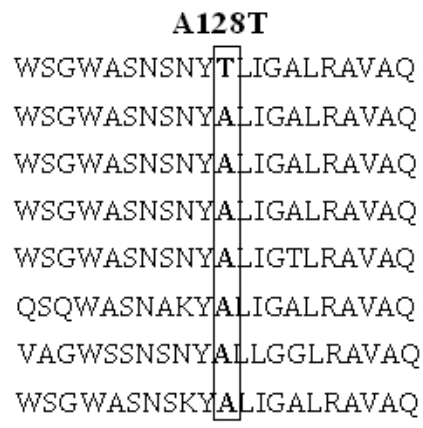

Figure 1. Comparison of the ND1 polypeptide region encompassing the Ala128Thr change (A128T) (bolded) among several species. in samples collected after chemotherapy, but in one of the patients we noticed the loss of the transition at position 3688. The level of the $3688 \mathrm{G}>\mathrm{A}$ transition in DNA from patient's 2 bone marrow collected at the moment of ALL diagnosis was $17 \% \pm 0.23 \%$, but this change was not found in the DNA isolated from this patient's blood and bone marrow collected at day 42 of treatment (Fig. 2 and Fig.3).

\section{DISCUSSION}

In the present study we sequenced the D-loop as well as 5 genes of mtDNA derived from bone marrow cells of 6 pediatric patients with ALL. Analysis of the mtDNA sequences showed a number of common polymorphisms, most of them located in the D-loop region. In one of the samples derived from a patient at the moment of ALL diagnosis a heteroplasmic transition at position 3688 of mtDNA was found. The $3688 \mathrm{G}>\mathrm{A}$ transition is located in the highly conserved region of ND1

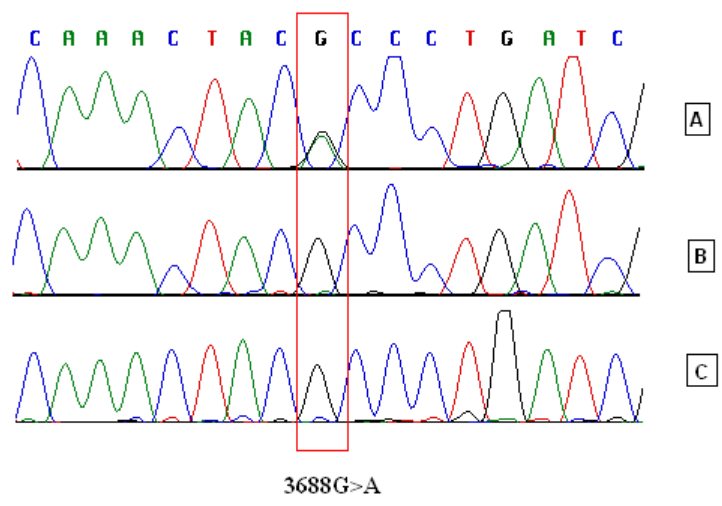

Figure 2. Molecular analysis of the ND1 gene in an ALL patient. Electropherograms of the ND1 gene showing the $3688 \mathrm{G}>\mathrm{A}$ transition only in a bone marrow sample collected at the time of leukemia diagnosis (A). (A) DNA isolated from bone marrow cells collected from the patient at the time of diagnosis. (B) DNA isolated from bone marrow cells collected from the patient at day 42 of treatment. (C) DNA isolated from the patient's blood. 


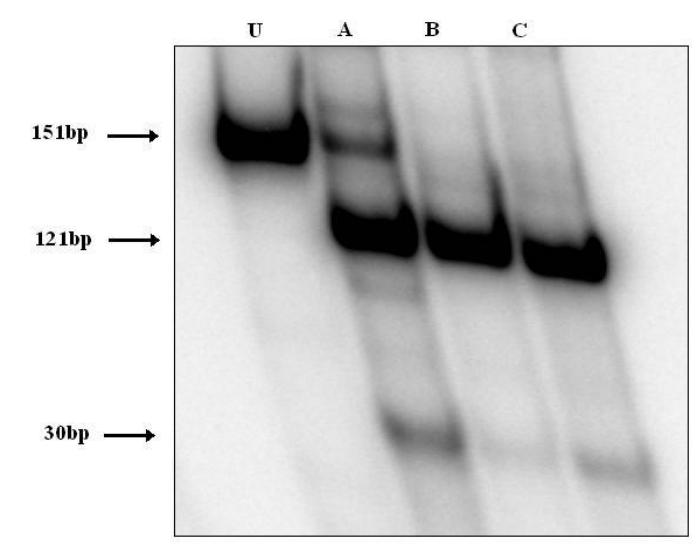

Figure 3. PCR-RFLP analysis for the transition 3688G $>$ A.

The region spanning codon 128 in the ND1 gene was PCR amplified and the $151 \mathrm{bp}$ PCR product was cut with Haell. The wild type sequence is cut into two fragments of $121 \mathrm{bp}$ and $30 \mathrm{bp}$. In the presence of the $3688 \mathrm{G}>\mathrm{A}$ mutation the Haell restriction site is lost, permitting discrimination between wild-type and mutated mtDNA. (A) DNA isolated from bone marrow cells collected from the patient at the time of diagnosis. (B) DNA isolated from bone marrow cells collected from the patient at day 42 of treatment. (C) DNA isolated from patient's blood. (U) uncut DNA

gene. This change, in a homoplasmic state, was previously described in one patient with Leigh syndrome, in whom it was associated with a strong reduction of complex I activity in both muscle and fibroblasts (Valente et al., 2009). We do not know if the 3688G $>$ A transition appeared in bone marrow cells of our patient as a consequence of malignant transformation because we did not have a sample collected before the patient was diagnosed with leukemia. However, we can speculate that, if the presence of this transition caused a reduction of complex I activity in a Leigh syndrome patient's tissues it could also cause dysfunction in bone marrow cells and can be considered as a pathogenic mutation. A decrease of the complex I activity could cause reactive oxygen species overproduction and lead to oxidative stress which could contribute to malignant transformation in bone marrow cells. Analyses of cell cultures derived from consecutive bone marrow specimens collected from our patient are required to obtain information about the influence of the $3688 \mathrm{G}>\mathrm{A}$ transition on cell physiology and to confirm the pathogenicity of the mutation and whether it has any influence on the course of treatment.

In our research we also wanted to check whether the mutation load can change in different treatment stages, as was previously described by He et al. (2003). The aim of chemotherapy is the elimination of cancerous cells with mutations and aberrations potentially dangerous to cell physiology. The $3688 \mathrm{G}>\mathrm{A}$ mutation, present in bone marrow cells collected from one patient with ALL, disappeared in the course of chemotherapy treatment (in the induction phase), therefore we can suspect that chemotherapy killed the cancerous cells and only healthy cells remained which were free of this mutation. In our considerations on the cause of the lack of detection of mutation in bone marrow samples taken at day 42 of treatment, we also have to take into account that bone marrow consists of heterogeneous populations of cells. In addition to hematopoietic stem cells we can also find endothelial, pluripotent and tissue commited stem cells as well as multipotential adult progenitor cells (Ratajczak et al.,
2004). This raises the question whether the first and second bone marrow sample collected from our patient contain the same proportions of cells from different populations? We cannot exclude that the differences in proportion of various cell types could be also responsible for the absence of mutation detection in the sample collected during treatment. Moreover, the heteroplasmy level of detected mutation was quite low so if in the second bone marrow sample there was a much lower level of cells of a specific type in which the mutation previously existed, its detection could be difficult or impossible. If the mutation would be nearly homoplasmic it would mean that it was present in almost all populations of cells in bone marrow and interpretation of such a result could be much easier. In this case the absence of mutation in the bone marrow sample after chemotherapy which was homoplasmic in the sample collected at the time of diagnosis could be more informative and we could suspect that its disappearance was caused by treatment. Mutations, whose levels change during patient treatment, could be potential biomarkers for monitoring treatment efficacy and disease in this patient.

In our study we were also interested whether chemotherapy causes mtDNA mutations. If mtDNA is sensitive to chemotherapeutics, then it might be possible to monitor changes in mtDNA sequence during treatment which could reflect treatment effectiveness. Comparative analyses revealed that there was no additional accumulation of polymorphisms or mutations in specimens colleceted after chemotherapy. It should be noted that in our study the examined group of pediatric patients with ALL is too small to draw conclusions about the lack of detrimental chemotherapeutic treatment effects on the mtDNA sequence. Moreover, only part of the mtDNA was analyzed and the potential mutations caused by chemotherapeutics could occur in the other coding regions of mtDNA. Such changes, if found, could be used as a genetic marker of DNA damage and might explain some of the adverse effects of treatment and also relapse of cancer.

It is conceivable that some mutations could contribute to the development of a cancer phenotype by changing cellular energy capacities, increasing free radical generation leading to further DNA damage and genetic instability and modulating apoptosis. Further studies to determine at what stage the somatic mtDNA mutation occurs could give an insight into the role of somatic mtDNA mutation in leukemia and carcinogenesis. The presence of a mutation does not prove that they play a causative role in carcinogenesis, however, it provides additional information about the contribution of mitochondria to this process. Moreover, if damage of the mitochondrial genome results in long term adverse effects, this knowledge may be helpful to develop agents which protect the mitochondrial genome during cancer.

\section{Conflicts of interests}

The authors report no conflicts of interest.

\section{Acknowledgements:}

The study was partly supported by the Faculty of Biology, University of Warsaw of intramural grant, BW 191115 and BW 501/86-102329 and by the minigrant G-37 of the Laboratory of Sequencing and Synthesis of Oligonucleotides of the Polish Academy of Sciences. 


\section{REFERENCES}

Buffler PA, Kwan ML, Reynolds P, Urayama KY (2005) Environmental and genetic risk factors for childhood leukemia: appraising the evidence. Cancer Investigation 1: 60-75. http://doi.org/10.1081/CNV200046402

Campbell M, Castillo L, Riccheri C, Janic D, Jazbec J, Kaiserova E, Konja J, Kovacs G, Kowalczyk J, Soycan LY, Kiss C, Schrappe M, Stary J, Dworzak M, Kappelmayer J, Szczepański T, Zimmermann M (2009) ALL IC-BFM 2009: A randomized trial of the I-BFM-SG for the management of childhood non-B acute lymphoblastic leukemia. Final Version of Therapy Protocol from 14 August 2009.

Chiaretti S, Zini G, Bassan R (2014) Diagnosis and subclassification of Acute Lymphoblastic Leukemia. Med J Hem Infect Dis 6: 1-14. http://dx.doi.org/10.4084/mjhid.2014.073

de Rooij JDE, Zwaan CM, van den Heuvel-Eibrink M (2015) Pediatric AML: From Biology to Clinical Management. J Clin Med 4: 127149. http://dx.doi.org/10.3390/jcm4010127

He L, Proctor SJ, Middleton PG, Blakely EL, Taylor RW, Turnbull DM (2003) Somatic mitochondrial DNA mutations in adult-onset leukemia. Lenkemia 17: 2487-2491. http://doi.org/10.1038/ sj.leu. 2403146

Kim HR, Shin MG, Kim MJ, Kim HJ, Shin JH, Suh SP, Ryang DW (2008) Mitochondrial DNA aberrations of bone marrow cells from patients with aplastic anemia. J Korean Med Sci 23: 1062-1067. http://doi.org/10.3346/jkms.2008.23.6.1062

Nordlund J (2007) Genome-wide single nucleotide polymorphism genotyping for identification of copy number variation and allelic imbalance affecting drug response in acute childhood leukemia.
Biology Education Centre and the Department of Medical Sciences, Uppsala University.

Pieters R, Schrappe M, Valsecch MG, de Rossi, Biondi A, Suppiah R, Felice M, Mann G, Ferster A, Janka-Schaub G, Stary J, Silverman L, Mechinaud F, Li CK, Nunez C, Holi L, Campbell M, Szczepański T, Thomson B, Rubnitz JE, Ancliffe P, Vora A, Peters C (2006) Interfant-06: International collaborative treatment protocol for infants under one year with acute lymphoblastic or biphenotypic leukemia. Sichting Kinderoncologie Nederland (SKION) Versie 1.0 April 2006.

Ratajczak MZ, Kucia M, Majka M, Reca R, Ratajczak J (2004) Heterogeneous populations of bone marrow stem cells - are we spotting on the same cells from the different angles? Folia Histochem Cytobiol 42: 139-146. http://doi.org/10.5603/4649

Rubnitz JE and Pui CH (1997) Childhood Acute Lymphoblastic Leukemia. The Oncologist 2:374-380.

Stary J, Zimmermann M, Campbell M, Castillo L, Dibar E, Donska S, Gonzalez A, Izraeli S, Janic D, Jazbec J, Konja J, Kaiserova E, Kowalczyk J, Kovacs G, Li CK, Magyarosy E, Popa A, Stark B, Jabali Y, Trka J, Hrusak O, Riehm H, Masera G, Schrappe M (2013) Intensive chemotherapy for childhood acute lymphoblastic leukemia: results of the randomized intercontinental trial ALL IC-BFM 2002. J Clin Oncol 31: 1-12. http://jco.ascopubs.org/cgi/ doi/10.1200/JCO.2013.48.6522

Valente L, Piga D, Lamantea E, Carrara F, Uziel G, Cudia P, Zani A, Farina L, Morandi L, Mora M, Spinazzola A, Zeviani M, Tiranti V (2009) Identification of novel mutations in five patients with mitochondrial encephalomyopathy. Biochimi Biophys Acta 1787: 491-501. http://dx.doi.org/10.1016/j.bbabio.2008.10.001 